\title{
Prevenção do câncer de mama: conhecimento de mulheres de uma unidade saúde da família
}

\author{
Breast cancer prevention: knowledge of women from a family health unit
}

Aline da Costa Viegas ${ }^{1}$ Rosani MaNFrin MUNIZ Daniela Habekost Cardoso Bianca Pozza dos Santos JANAÍNA BAPTISTA MACHADO ${ }^{\text {II }}$ LUIZ GUILHERME LINDEMANN ${ }^{1}$ ${ }^{\mathrm{I}}$ Universidade Federal de Pelotas. Pelotas/RS - Brasil

"Universidade Federal do Rio Grande do Sul. Porto Alegre/RS - Brasil
Resumo Objetivo: apresentar o conhecimento de mulheres participantes de uma Unidade Saúde da Família (USF) em relação à prevenção primária e secundária do câncer de mama. Método: pesquisa qualitativa e descritiva em uma Unidade Saúde da Família de Pelotas, Rio Grande do Sul, desenvolvida no domićlio de 20 mulheres, por meio de entrevistas. Para a análise dos dados, utilizou-se a temática de Braun e Clarke. Respeitaram-se os princípios éticos. Resultados: o conhecimento das participantes sobre a prevenção do câncer de mama está atrelado aos exames de detecção precoce como o autoexame, a mamografia e o exame clínico das mamas. Parte delas destacou cuidados para a prevenção primária da doença. Considerações Finais: o conhecimento dessas mulheres mostrou semelhanças no que diz respeito à prevenção do câncer de mama, pois partilham de saberes para a sua prevenção. Contudo, existem saberes únicos, experiências de vida, desejos e temores, que demonstram a singularidade de cada mulher diante da temática abordada.

Palavras-chave: Saúde da Mulher. Prevenção de Doenças. Neoplasias da Mama. Conhecimento.

ABstract Objective: to present the knowledge of women participating in a Family Health Unit in relation to primary and secondary prevention of breast cancer. Method: qualitative and descriptive research in a Family Health Unit of Pelotas, Rio Grande do Sul, developed at the household of 20 women, through interviews. For the data analysis, the Braun and Clarke themes were used. Ethical principles were respected. Results: the participant's knowledge about breast cancer prevention is linked to the early detection tests such as self-examination, the mammography and the clinical examination of the breasts. Part of them highlighted care for primary prevention of the disease. Final Consideration: the knowledge of these women presented similarities regarding the prevention of breast cancer, because they share knowledge for their prevention. However, there are unique knowledge, life experiences, desires and fears, which demonstrate the singularity of each woman in the face the selected theme.

Keywords: Women's Health. Disease Prevention. Breast NeOPlasms. KNOWLEDGE. 


\section{INTRODUÇÃO}

O câncer é considerado um importante problema de saúde pública no Brasil, e diante da criação do Sistema de Informação de Mortalidade, na década de 1970, observou-se que, entre mulheres, havia uma alta taxa de prevalência e de mortalidade por câncer de mama. ${ }^{1}$ De acordo com o Instituto $\mathrm{Na}$ cional de Câncer, foram estimados, no ano de 2018, cerca de 59.700 casos de câncer de mama no Brasil, correspondendo a aproximadamente $25 \%$ dos casos novos a cada ano.

O desenvolvimento do câncer de mama é decorrente de diversos fatores, sendo esses biológicos ou ambientais. Como fatores biológicos, citam-se aspectos endócrinos e genéticos. O de caráter hereditário (genético) corresponde a cerca de $5-10 \%$ do total de casos. Já em relação aos fatores endócrinos, o risco está associado à história de menarca precoce, menopausa tardia, primeira gravidez após os 30 anos de idade, nuliparidade e terapia de reposição hormonal. Quanto aos fatores ambientais, incluem-se a exposição a radiações ionizantes, a ingestão regular de bebida alcoólica, obesidade e o sedentarismo. ${ }^{2}$

O câncer de mama é uma doença que gera impacto no funcionamento físico, bem como, nos aspectos psicossociais, o que leva a pessoa a ter perda de confiança associado ao medo da incapacidade e da morte. Estima-se que quase $30 \%$ desses casos poderiam ser evitados por meio da prevenção primária, que compreende todas as ações que visam à supressão dos fatores geradores da doença e entre as medidas passíveis de mudança mais importantes estão: a amamentação, a alimentação saudável, a prática de exercícios físicos, a ingestão equilibrada de bebidas alcoólicas e o controle do peso. ${ }^{2}$

$\mathrm{O}$ diagnóstico precoce do câncer de mama se configura como estratégia de combate no âmbito da prevenção secundária, sendo realizado através da mamografia, do exame clínico das mamas (ECM) e da prática do autoexame das mamas. ${ }^{3}$ Uma das ações relacionadas ao diagnóstico precoce dessa doença é manter a população alerta para os sinais e sintomas suspeitos. É nesse cenário que fica evidente que no momento em que as mulheres conhecem as estratégias de prevenção do câncer de mama, as possibilidades para realizar os cuidados aumentam, além de ampliar a sua autonomia no autocuidado e na solicitação de uma avaliação adequada nas consultas de rotina. ${ }^{4}$

Diante da contextualização apresenta$\mathrm{da}$, entende-se que compreender o que um grupo de mulheres conhece sobre as ações de prevenção do câncer de mama é de suma importância. Assim, este estudo tem por objetivo apresentar o conhecimento de mulheres participantes de uma Unidade Saúde da Família (USF) em relação à prevenção primária e secundária do câncer de mama.

\section{Métodos}

Pesquisa de abordagem qualitativa e descritiva, desenvolvida em uma USF do município de Pelotas, Rio Grande do Sul. As participantes do estudo eram mulheres que utilizavam a USF e realizaram os exames preventivos do câncer ginecológico no primeiro semestre de 2016, sendo a amostragem do tipo intencional, por meio da consulta do livro de registros de coleta do 
exame citopatológico que permanecia na sala de consulta de enfermagem. As mulheres estavam compreendidas na faixa etária dos 40 a 69 anos de idade.

O período da coleta de dados foi de junho a outubro de 2016, por meio de entrevista semiestruturada no domicílio, e o registro dos encontros foi descrito em notas de campo. As questões de pesquisa compreenderam informações em relação a dados demográficos, fatores de risco ou proteção para o câncer de mama e uma questão norteadora: fale o que a senhora sabe sobre prevenção e exames do câncer de mama. Ainda, havia questões de apoio que abarcavam aspectos específicos que deveriam estar presentes na entrevista como a prevenção primária e secundária da doença. Posteriormente ao encontro com a participante e gravação da entrevista, foi realizada a transcrição.

Os critérios de inclusão foram: residir na área adstrita da USF; estar na faixa etária dos 40 a 69 anos de idade; permitir a gravação de áudio durante a entrevista; consentir com a divulgação dos dados nas mídias (escrita e digital) e no meio científico. E, como critérios de exclusão, foram: apresentar dificuldades de comunicação verbal; ter história familiar de câncer de mama em primeiro grau. Para a análise de dados, utilizou-se a análise temática. ${ }^{5}$

Esta pesquisa respeitou os princípios éticos das diretrizes sobre pesquisa com seres humanos, norteadas pela Resolução $\mathrm{n}^{\circ}$. 466/12 do Conselho Nacional de Saúde. O projeto foi avaliado pelo Comitê de Ética em Pesquisa da Faculdade de Enfermagem da Universidade Federal de Pelotas, obtendo parecer favorável sob o número CAAE:
56981516.1.0000.5316. A fim de resguardar a identidade e manter a privacidade, as participantes foram identificadas por nomes fictícios escolhidos por elas, seguido da idade.

\section{RESUlTADOS E DISCUSSÃo}

Compuseram o grupo de participantes desta pesquisa um total de 20 mulheres, as quais responderam quanto à prevenção do câncer de mama. A prevenção primária e a secundária (detecção precoce) do câncer de mama são essenciais para o controle dessa doença. A primeira tem o intuito de evitar o aparecimento da doença, sendo suas ações direcionadas para a diminuição da exposição a fatores de risco. Logo, a prevenção secundária tem por objetivo descobrir o câncer em uma fase inicial, mas não há uma redução na incidência, porém, pode haver na mortalidade. ${ }^{6}$

De acordo com o Ministério da Saúde, controlar o câncer de mama configura-se em uma das prioridades da Política Nacional de Saúde devido a essa doença ser considerada um grave problema de saúde pública. ${ }^{6}$ Desse modo, optou-se por focar as dimensões da prevenção primária e secundária desse tipo de neoplasia, segundo a perspectiva de mulheres que realizam práticas de cuidado à saúde com as mamas em uma USF.

\section{Prevenção primária do câncer de mama: práticas de cuidado das mulheres de uma USF}

Algumas participantes afirmaram desconhecer como prevenir o câncer de mama, no sentido da prevenção primária, uma vez que referiram nada fazer: 
Nem sei o que fazer para prevenir o câncer. Não faço ideia (Celina, 51 anos de idade).

Outros cuidados como é que vou prevenir eu não sei, não sei como fazer no caso. Daí se sentir, vou procurar o médico (Helena, 53 anos de idade).

Entretanto, outras mulheres consideraram que fazer o autoexame mensal, ou mesmo, fazer o exame clínico das mamas, é a melhor maneira de prevenir:

Não faço nada [prevenir o câncer de mama]. Só essa avaliação quando eu tenho um tempinho que eu lembro. Porque geralmente eu não lembro [...]. E no postinho, mas só quando eu faço pré-câncer, que elas me examinam toda vez [mamas] (Graciela, 41 anos de idade).

A gente tem que se prevenir, fazer o exame de toque uma vez por mês que todo mundo pede [...], se tiver um carocinho tem que procurar alguma coisa [...]. Não sei se tem alguma coisa a mais que a gente pode se prevenir. A gente sempre quando pode se prevenir, a gente procura se prevenir, é melhor para a gente (Fabiana, 42 anos de idade).

Para algumas mulheres do estudo, há um desconhecimento sobre a prevenção primária do câncer de mama, sobretudo, atrelado aos fatores de risco modificáveis, como uma forma de evitar a doença. Fato que pode estar associado com o pouco debate nos meios midiáticos em relação às possibilidades de prevenção primária da doença, e também, não ser um assunto de destaque nos ambientes de assistência à saúde, como nas USFs. Nesse sentido, o entendimento das mulheres acerca do autoexame e do exame clínico das mamas se relaciona a uma maneira de evitar a doença, ou mesmo, na presença de sintomas buscar o cuidado com o profissional da saúde. De acordo com o Ministério da Saúde, há uma multicausalidade para o câncer de mama, sendo que a população feminina e o envelhecimento são os principais fatores de risco. ${ }^{7}$
Um estudo na Escócia com 31 mulheres evidenciou que existem poucos programas de educação em saúde em relação aos hábitos de vida para a prevenção do câncer de mama. Com as poucas evidências da comunicação e da influência dos fatores de risco no padrão de comportamento das pessoas, o que se assemelha às participantes do presente estudo. ${ }^{8}$

Mulheres imigrantes sobreviventes ao câncer de mama que viviam nos Estados Unidos creem que fatores modificáveis estão relacionados ao surgimento da doença como o estresse e o estilo de vida como o excesso de trabalho, cotidiano intenso e pouco tempo para cuidar de si ou da família. Também, mencionaram a associação do câncer de mama com a dieta norte-americana, mas também, do país de origem, sendo referido o mau hábito alimentar, com exagero na ingestão dos alimentos e na má nutrição. ${ }^{9}$

Algumas mulheres citam os cuidados alimentares como estratégia para prevenir o câncer de mama, como a ingestão de legumes e de gordura:

Eu vejo falar sempre sobre alimentação, porque a gente come, porque é o que mais previne [...], não sei se existe outro tipo de prevenção (Alicia, 62 anos de idade).

Olha, me disseram que comendo bastante brócolis, mas também não sei se é verdade. Outras coisas não fiquei sabendo ainda que eu posso prevenir. Ninguém me explicou (Valéria, 50 anos de idade).

Além da alimentação que todo mundo diz que alimentação tinha a ver, que eu cuido bastante da alimentação, comer legumes crus e bem lavados, que isso aí não é só para o câncer, como para qualquer tipo de saúde. Isso é uma coisa que eu cuido bastante (Helena, 53 anos de idade).

Tem pessoas que falam muito dos alimentos. Alimentos assim, muita gordura (Vanda, 44 anos de idade). 
Essas participantes entendem que ingerir alimentos específicos ou evitá-los é um modo de prevenir o câncer de mama. Chegam a destacar que esse cuidado vai além da doença, podendo influenciar de uma maneira em geral na manutenção da saúde. Em uma pesquisa desenvolvida no Estado do Paraná, com 193 mulheres, foi identificado que elas associavam os fatores de risco modificáveis como a obesidade, o alcoolismo e o tabagismo ao surgimento do câncer de mama. ${ }^{10}$

Em concordância ao resultado encontrado, o estudo de Khazaee-Pool realizado com 24 mulheres iranianas revelou que as participantes relacionaram os hábitos saudáveis como a dieta, a prática de exercícios físicos e os exames com a prevenção do câncer de mama. Até mesmo, algumas informaram terem diminuído a presença da gordura na alimentação. ${ }^{11}$

Ainda, o cigarro igualmente foi apontado pelas mulheres como um hábito que coloca as pessoas em risco para o câncer.

\begin{abstract}
Ela [amiga com câncer] é fumante. Não sei se ela parou agora, mas, muito fumante, ela não comia para fumar. [...] Ajuda também, tudo ajuda, tudo que é de mal ajuda [aparecimento do câncer de mama], tudo influencia para ruim (Rosinha, 58 anos de idade).

O cigarro também, que na verdade, provoca vários tipos de câncer, e isso eu já ouvi comentários (Vanda, 44 anos de idade).
\end{abstract}

O tabagismo sinaliza perigo, conforme a visão de algumas das participantes, em relação ao risco do câncer. A associação do tabagismo ao câncer de mama foi considerada como fator de risco em estudo com 544 trabalhadoras de um serviço calçadista na cidade de Porto Alegre/RS. ${ }^{12}$
No presente estudo, embora poucas participantes (apenas seis) tenham mencionado os cuidados em relação à prevenção primária do câncer de mama, deve-se considerar as colocações referentes aos fatores de risco já abordado por elas. Dessa maneira, entende-se que as pessoas devem conhecer os fatores modificáveis que interferem no aparecimento do câncer, como o tabagismo, o alcoolismo, a alimentação inadequada, o sedentarismo, o aumento de peso, entre outros específicos para o câncer de mama, como menarca, paridade, hormônios e amamentação, e os gerais, como idade, sexo, etnia, hereditariedade, exposição a agentes cancerígenos. ${ }^{13}$ Desses fatores mencionados, muitos não foram relacionados ao aparecimento do câncer.

Também fica evidente que na concepção de duas mulheres, prevenir é ter a oportunidade de detectar precocemente o câncer de mama, a partir da realização dos exames.

Tenho certeza que isso o SUS (Sistema Único de Saúde) vai correr ligeiro, porque prevenir é para isso (Santiaga, 54 anos de idade).

Eu acho que agora eles estão bem atualizados para prevenção, para o começo [...], porque tem muitas pessoas que vão quando já está bem adiantado (Rosinha, 58 anos de idade).

Nota-se que a prevenção tem sinônimo de detecção precoce, uma vez que fica implícito que a atividade preventiva ocorrerá na presença de alteração na mama, pois, tem-se a ideia de que os profissionais da saúde do sistema público agirão rapidamente. Também, evidencia-se o entendimento de que a prevenção consiste em descobrir a doença no começo de seu desenvolvimento. 
Para algumas mulheres de um estudo francês e que participaram de grupos focais, e também, de programas de rastreamento do câncer de mama, a prevenção foi considerada relevante, constituindo-se em regularidade nas consultas com ginecologistas e no exame mamográfico. ${ }^{14} \mathrm{O}$ que também representa o pensamento de algumas das participantes deste estudo, pois, quando o assunto era prevenção da doença, os exames foram o destaque, em detrimento aos hábitos de vida.

Para algumas mulheres deste estudo, as ações curativas sobressaíram-se às preventivas:

Quando é só uma prevenção, tudo bem! Mas agora, quando tu estás com um problema que tu precisas, é demorado, ai se torna difícil [atendimento nos serviços de saúde] (Alicia, 62 anos de idade).

Mais ligeiro esses tipos de exames, ainda mais quem já tem esse problema, se é uma coisa que não tem, vai fazer por fazer, assim para ver como é que está, ainda passa (Neli, 57 anos de idade).

Para uma minoria das mulheres, há uma desqualificação da prevenção em comparação com as ações curativas, ao passo que referem que se "É só uma prevenção, tudo bem!" e "Vai fazer por fazer!" Assim, acredita-se que parece haver influência do modelo curativista nos discursos das participantes que, possivelmente, tenha origem nas práticas dos profissionais que pautam suas ações e seus esforços prioritariamente na presença das doenças e não para evitá-las.

Mas também, acredita-se ser necessário levar em consideração que as ações de prevenção primária demandam a modificação de hábitos de vida, os quais são construídos e moldados no decorrer da existência e sofrem influências do âmbito cultural e social das pessoas. Dessa forma, modificá-los pode exigir mudanças nesses âmbitos da vida das mulheres.

Em uma pesquisa foi evidenciada a colisão entre dois modelos assistenciais, isto é, o hegemônico, centrado no médico, no âmbito biológico e nas doenças, na busca da cura, sem considerar o contexto social, e o contra-hegemônico, representado pela Estratégia Saúde da Família, o qual, além de considerar a cura, prioriza a promoção da saúde e a prevenção das doenças, incluindo a família e a comunidade como centro de cuidado. ${ }^{15}$

Um estudo realizado no Ceará indicou que as pessoas usuárias dos serviços de saúde também têm dificuldades de entender a mudança de paradigma. Ainda, buscam uma atenção imediata, com resolutividade da queixa e da cura, com valorização da especialidade e dos exames, ignorando a lógica da corresponsabilidade, pois, as pessoas foram culturalmente acostumadas a buscar as Unidades Básicas de Saúde na vigência de adoecimento e não para promoverem sua saúde. ${ }^{15}$

\section{Práticas de cuidado das mulheres na prevenção secundária do câncer de mama}

As participantes do estudo mostraram preocupação com a saúde de suas mamas, desenvolveram práticas de cuidado, as quais entenderam ser importante identificar o surgimento da doença o mais precoce possível. Quando iniciado o diálogo sobre as práticas preventivas do câncer de mama, o autoexame obteve destaque.

Pelo menos uma vez por mês [autoexame], mas eu faço às vezes até mais, e graças a Deus, não sinto nada mesmo. Na hora do banho, acho que é a melhor hora (Helena, 53 anos de idade). 
As mulheres apontam diferentes periodicidades para a realização do autoexame das mamas. Algumas mantêm uma rotina regrada (diária ou mensal) para a sua realização, enquanto outras nem tanto (quando lembram) e utilizam períodos como o anterior e posterior à menstruação. Para elas, existem momentos oportunos, como durante a higiene corporal, ao se vestirem, ao se deitarem ou durante a hidratação da pele. Momentos em que podem identificar alguma alteração nas mamas.

Em uma investigação foi identificado que $89,2 \%$ (75) das mulheres já haviam feito o autoexame mamário. E $42,8 \%$ (36) o realizavam mensalmente nos últimos seis meses precedentes à pesquisa. ${ }^{16}$ Conforme o Ministério da Saúde, a partir dos anos 1980/1990 ocorreram campanhas educacionais que tornaram popular o autoexame, que era orientado a partir de uma técnica padronizada e considerada oportuna para o rastreamento do câncer de mama. Contudo, na atualidade, não é mais recomendado pelo órgão governamental como uma estratégia de rastreamento da doença, mas sim, como uma prática eventual de observação e de palpação da mama, sendo uma estratégia de diagnóstico precoce, por meio do autoconhecimento da mama no padrão normal e com sinais de alerta. ${ }^{6}$

As práticas de cuidado são direcionadas pelos profissionais da saúde em relação à orientação do autoexame das mamas. Sobretudo, das enfermeiras da Unidade Saúde da Família da área de abrangência do território das mulheres.

Eles [profissionais] dizem que é para a gente tomar banho, passar a mão e ver algum carocinho, procurar se dói [...], isso eu faço em casa [...]. Se aparece um caroço, tem que procurar o médico
[...]. Ela [enfermeira] me falou quando a senhora tiver um tempinho debaixo do chuveiro, é a coisa melhor que tem da gente apalpar direitinho e se achar alguma coisinha, então a senhora fica atenta e vem (Santiaga, 54 anos de idade).

A orientação dos profissionais para a realização do autoexame das mamas, principalmente das enfermeiras da USF, direciona para a prática de realização do autoexame com frequência preestabelecida, em momentos peculiares como durante o banho e com o objetivo de identificar possíveis anormalidades, por exemplo, o nódulo mamário. Esse saber segue um padrão de comportamento para a prática de cuidado à saúde dessas mulheres, pautado nas recomendações dos profissionais da saúde.

Esse "padrão de comportamento" mencionado por muitas participantes foi modificado, uma vez que de acordo com o $\mathrm{Mi}$ nistério da Saúde não há necessidade de uma padronização do autoexame, mas uma conscientização das modificações mamárias usuais nos ciclos da vida e dos sinais e sintomas do câncer de mama. ${ }^{6}$

O autoexame das mamas também constitui uma prática de conhecimento do corpo, sem ter prazos de avaliação determinados ou de momentos específicos:

\begin{abstract}
A própria enfermeira do posto onde eu faço o pré-câncer disse que levanta o braço e começa a palpar aos poucos de um lado para o outro para cima e para baixo. [...] Só para conhecer a mama mesmo, se sentisse algum sinal diferente, é para procurar recurso (Estefanie, 55 anos de idade).
\end{abstract}

$\mathrm{Na}$ compreensão da participante, o autoexame é um momento de conhecimento do próprio corpo, no qual é possível identificar sinais patológicos e buscar auxílio nessa 
ocasião. Ela não indica periodicidade, mas uma oportunidade de se tocar e de se conhecer. Atitudes que estão em consonância com as recomendações do Ministério da Saúde.

A indicação vigente do autoexame das mamas é de que a mulher conheça suas mamas e na constatação de modificações suspeitas, procure o profissional da saúde, contrariamente à recomendação de passos e de frequência predeterminados, sendo assim, a prática da descoberta precoce da neoplasia mamária evolui do autoexame para o autoconhecimento. Fato constatado pelo Instituto Nacional do Câncer (INCA), em que de três mulheres com câncer de mama, duas identificam sozinhas sinal ou sintoma da doença. ${ }^{7}$

Contrapondo com o dado já mencionado, se para algumas mulheres o autoexame das mamas faz parte da rotina, outras não conseguem manter a realização da prática como um hábito de cuidado:

Tenho medo de fazer [autoexame]. Como eu te falei, eu sinto um carocinho assim de repente nem é nada, como me dizem que é quando a gente está para menstruar dá uns carocinhos, só que eu sou tão medrosa, que toda vez que eu me examino, eu sinto, e eu acho que é um pouco isso que eu já não faço [...]. Eu prefiro deixar os outros fazer. [...] Eu não gosto nem de mexer! Essa é a realidade (Graciela, 41 anos de idade).

Observa-se que para Graciela é difícil realizar o autoexame das mamas, pois tem medo de fazer pela possibilidade de encontrar alguma alteração. No que diz respeito ao autoexame, em uma investigação em Juiz de Fora/MG com 820 mulheres foi evidenciado que a maioria delas não se declarava capaz de diferenciar o tecido mamário normal do possivelmente alterado. Além do mais, grande parte não tinha conhecimento do momento oportuno para a sua realização. ${ }^{17}$

De acordo com a participante Rosinha:

Se eu não sinto nada, se eu não tenho nada, eu nem vou a lugar nenhum. Mas quando sentir alguma coisa, que ache que não estou bem, eu já vou procurar ajuda (Rosinha, 58 anos de idade).

Não ter sintomas ou alterações corporais para as mulheres são indícios de que o organismo está bem, portanto, pode não haver necessidade de buscar avaliação do profissional.

Eu acho que se tu tocares que tem alguma coisa diferente, tem que procurar uma orientação médica para fazer um exame (Marcia, 48 anos de idade).

Se a gente sente alguma coisa, ir ao médico! Isso eu fiz quando estava para menopausa, que eu sentia dor, meu seio inchava, fui ao médico, não fiquei esperando passar. É o que a gente pensa (Elisa, 56 anos de idade).

Eu não estava sentindo nada na verdade. Se eu tivesse sentindo alguma coisa, eu acho que ficaria meio preocupada e já iria até procurar fazer particular no caso (Vanda, 44 anos de idade).

Fica evidente no ideário de algumas mulheres que a não existência de sinais e sintomas de uma doença configura segurança, dessa forma, tudo no organismo está bem. Na compreensão delas, a busca pelo profissional da saúde deve ocorrer, especialmente, quando há algo suspeito. Com a estratégia de conscientização proposta pelo Ministério da Saúde, a mulher deve conhecer seu corpo, e se nas eventuais palpações identificar algo diferente, buscar a avaliação profissional. ${ }^{6} \mathrm{O}$ que corrobora com as práticas de cuidado das participantes do estudo, que acreditam que na presença de sinais e sintomas o profissional da saúde deve ser acionado. 
Em uma investigação no Irã, as mulheres devido a não sentirem alterações mamárias, não temiam o câncer, acreditando que essa doença ocorria somente em pessoas com a idade mais avançada e/ou com histórico familiar. ${ }^{11}$ Em contrapartida, estudo com 156 mulheres que visou identificar os principais fatores associados à demora no diagnóstico da neoplasia mamária, a atitude de risco esteve relacionada à ausência de sintomas e a não adesão à mamografia na faixa etária recomendada. ${ }^{18}$

As mulheres ainda pontuam que estão familiarizadas com o exame clínico das mamas, e, com frequência mencionam a enfermeira da USF que realiza o procedimento:

Tem a [nome da enfermeira] que faz o pré-câncer e sempre examina [exame clínico das mamas]. [...] para mim, é tranquilo. Não vejo nada de anormal, não tem nada demais (Alicia, 62 anos de idade).

Elas [profissionais da USF] sempre examinam. Acho normal porque se tu vais procurar um médico é para te dizer o que é e ser atendida. E ele tem que fazer a parte dele (Estefanie, 55 anos de idade).

A maioria das mulheres do estudo considera que o exame clínico das mamas é uma prática de cuidado para a prevenção do câncer de mama. Esse momento também possibilita para as mesmas um período de tranquilidade, como pode ser observado no depoimento da seguinte participante:

Eu gosto de fazer esse exame. Pelo menos, a gente sabe que não tem nada (Mara, 49 anos de idade).

Nessa avaliação e no encontro com a enfermeira, a mulher tem a oportunidade de garantir que não tem alteração na mama.
Desse modo, elas descrevem a experiência e o momento oportuno para a realização do exame clínico das mamas, o qual consideram importante para o cuidado do seu corpo.

Em um estudo com 1.596 mulheres em Rio Grande/RS, foi verificado que 191 (12\%) consideravam o exame clínico da mama realizado por um profissional da saúde como estratégia de detecção precoce do câncer mamário, sendo destacado o baixo conhecimento desse grupo. ${ }^{4} \mathrm{O}$ que diverge da presente pesquisa, em que a maioria das mulheres ressaltou o exame clínico como forma de cuidado. Dado que pode estar relacionado com a participação das mulheres nas ações de prevenção do câncer na USF, e, portanto, possivelmente construíram conhecimentos no que tange às estratégias de cuidado.

Além disso, as experiências com a mamografia foi um destaque para as mulheres deste estudo, sendo essa técnica uma estratégia para o cuidado da mama:

Não achei nada assim, difícil de fazer o exame. Achei bem agradável (Vanda, 44 anos de idade). É bom fazer porque a gente fica informada (Maria 2, 57 anos de idade).

Para algumas das participantes do estudo, o exame mamográfico traz benefícios em relação à saúde mamária, fato importante que as fazem realizar o exame periódico. Em uma investigação na França, mulheres que participavam de um programa de rastreamento do câncer de mama afirmaram que a mamografia não ocasionava risco para a saúde, sendo apenas desconfortável sua realização. ${ }^{14}$

As experiências negativas em relação à mamografia fizeram que outras mulheres 
ressaltassem o incômodo do exame. No entanto, reconhecem vantagens para o cuidado à saúde.

O que dói é a mamografia. Que troço incômodo aquilo, será que eles não vão inventar um aparelho que dói menos? A gente sai de lá dolorida. [...] Eu não sei se é falta de experiência da pessoa que opera a máquina, não sei se é a máquina mesmo que é incômoda, porque tem muita gente que não reclama, mas a mim, dói muito [...]. E dói as duas, então tu ficas pensando assim, será que é a minha mama que está com problema? Ai tu já começas a achar que o problema é tu. [...] Aquilo ali é uma coisa que dói na hora, até tu podes ficar dolorida o resto do dia, mas depois passa. É para o teu beneficio. Tem horas que tu tens que fazer algum sacrificio. Nem tudo também vai ser tão fácil assim (Celina, 51 anos de idade).

Embora o exame mamográfico ocasione desconforto, as participantes referiram que é "um mal necessário", visto os benefícios que podem ser alcançados. Nas entrevistas, elas procuram explicações para esse incômodo, indicando as possíveis razões do sintoma. Todavia, consideram que com a evolução dos equipamentos ficou mais fácil realizá-lo, havendo críticas por parte das mulheres do estudo quanto às mulheres que não o fazem. Ademais, fica evidente o quão importante são as orientações em relação aos exames, neste caso, a mamografia, o que poderia ser determinante na escolha de fazê-la ou não, na redução da ansiedade e do medo do desconhecido.

No Canadá, um grupo de mulheres considerou a mamografia como um ponto positivo no rastreamento do câncer de mama, manifestando que esse exame é a melhor forma de se proteger contra a doença, especialmente por a temerem e ter empatia com quem já a teve. ${ }^{19}$
No Reino Unido, em pesquisa qualitativa com 22 mulheres que faziam o rastreamento para o câncer de mama e com 18 profissionais entre radiologistas e técnicos em radiologia, as mulheres não percebiam qualquer risco relacionado ao exame mamográfico, conferindo a ideia de que os desconfortos ocasionados era algo inevitável para uma razão importante, levando em conta o ditado popular: "É melhor prevenir, do que remediar”. Declararam que faltava preparo para iniciarem a experiência do rastreio mamográfico, salientando que seria válido um encontro com o profissional anteriormente ao exame a fim de conhecerem e terem orientações adequadas sobre o procedimento, embora tenham percebido ajustes nos mamógrafos que as deixavam mais confortáveis. ${ }^{20}$

Já para outras participantes, o medo da dor ocorreu anteriormente à experiência com o exame, pois quando o fizeram, não tiveram a vivência desse sintoma durante a mamografia:

Eu tinha medo [fazer mamografia], todo mundo dizia que doía, e eu tenho o seio grande, todo mundo dizia que eles apertavam muito, juntavam uma parte na outra e eu dizia "Meu Deus do céu!'. Eu tenho tanto seio, e vai doer mais ainda. Fiquei com medo de fazer [...]. Cheguei para a moça falando, tenho muita dor no seio, e ela foi tão boazinha comigo, que eu não senti nada. Valeu [fazer a mamografia], eu não me arrependo de ter feito, com aquela primeira vez assim dá para dizer que eu faria de novo (Graciela, 41 anos de idade).

O medo que as pessoas têm. É o medo que as pessoas têm de se machucar e de que dói [...]. Mas isso das mulheres não fazerem a mamografia e não fazer o pré-câncer é de medo [...]. Tem mulheres que vêm de uma excursão de Arroio Grande para fazer, cinco mulheres com 50 
e poucos anos nunca tinham feito isso de medo, porque umas passam para as outras que é muito dolorido, que é muito isso e muito aquilo e têm medo (Maria 1, 55 anos de idade).

No grupo em que essas participantes vivem, há uma construção ideacional sobre a mamografia como um exame que ocasiona dor, porém, ao se depararem com o procedimento perceberam que nem todas as pessoas têm a mesma sensibilidade. Também referiram que a postergação do exame por algumas mulheres pode ser em decorrência do medo da dor. Dado semelhante foi encontrado em um estudo, uma vez que algumas mulheres também não sentiram dor na realização da mamografia. ${ }^{20}$

A dor constitui uma das razões para algumas mulheres pensarem em não realizar a mamografia, assim como o exame clínico das mamas:

Tenho medo, porque elas apertam tanto, que dói. No momento que dói, assim, eu fico pensando, aperta tanto, daí que vai dar problema. Não sei se realmente é o que eu penso [...]. Na realidade, a mamografia que eu fiz eu não senti, e dos dedos aqui no postinho eu sinto quando elas apertam, elas apertam com força. Eu tenho medo é de machucar. [...] Medo que eles apertem muito com os dedos, tenho medo que apertam muito com o aparelho, então eu não queria fazer por isso, por medo [...]. Se bem que eu também não sei de repente se isso vem bem lá embaixo numa parte. De repente eles têm que apertar mais que é para pode sentir (Graciela, 41 anos de idade).

Observa-se que as mulheres do estudo narram experiências dolorosas na realização dos exames, dessa forma, gerando dúvidas de fazer ou não o cuidado da mama, e se o próprio poderia ocasionar lesões mamárias.
Em um estudo, o medo esteve relacionado com o desconforto e com as radiações do exame mamográfico. ${ }^{19}$ Outra pesquisa evidenciou que mulheres mencionavam a dor com frequência na experiência com a mamografia, relacionada à compressão da mama, sendo que algumas participantes chegaram a referir que tinham que "lutar" para suportar a dor. ${ }^{20}$

Em uma revisão sistemática meta-síntese qualitativa, que objetivou identificar as barreiras para o rastreamento do câncer de mama, foi evidenciado o medo da dor e a possibilidade de o exame apontar a doença. Tal estudo partiu da avaliação de 21 artigos que compreendeu as atitudes de 1.084 participantes do sexo feminino. ${ }^{21}$

Dependendo do local da realização do exame de mamografia, as experiências das participantes podem ser consideradas diferentes, assim, na vigência de experiências negativas pensam em pagar o exame como forma de garantir um atendimento adequado. Também, mencionam já terem realizado o exame em mais de um serviço, e por isso, as mulheres distinguem clínicas de imagens adequadas das que não são e sabem que têm a possibilidade de se sentirem confortáveis.

Tem pessoas que dizem, como a minha mãe mesmo dizia: Eu não vou fazer mais porque doeu muito! Eu disse: Mãe, não vai deixar de fazer porque tem outras. Eu falei que en fiz na [clínica de imagem e radiologia] e fui bem atendida lá, eu falei para ela fazer de novo [...]. E eu acho que toda mulher que me disser que tem medo, eu vou sempre aconselhar para fazer (Vanda, 44 anos de idade).

Elas referem que o exame mamográfico deve ser realizado sempre, mesmo que seja preciso trilhar outros caminhos, por 
exemplo, buscar outros locais que seja feito de modo diferente, o que poderia ocasionar menos dor. Além disso, as mesmas compreendem a importância de informarem e sensibilizarem outras mulheres a realizarem a mamografia devido aos benefícios alcançados a partir do exame.

Em uma investigação no Reino Unido com mulheres usuárias dos serviços de saúde e profissionais, foi identificado que as mulheres não voltaram a realizar mamografia em consequência de difíceis experiências no serviço e pela dor intensa na mama. ${ }^{20} \mathrm{~A}$ inadequação dos serviços de rastreamento para o câncer de mama também foi evidenciada em outro estudo, o que configurou uma das barreiras para a sua adesão. ${ }^{21}$

Apesar dos desconfortos e da ausência de sintomas, pelo menos duas mulheres explicitaram que a mamografia é um dever com a própria vida, como observado nos depoimentos:

É um desconforto fazer a mamografia [...], mas a gente tem que fazer uma coisa que a gente corre risco. É obrigada a fazer! (Mara, 49 anos de idade).

Eu sei que é uma obrigação, é um dever com a minha vida (Elisa, 56 anos de idade).

Para essas mulheres, não fazer a mamografia é considerado como ausência de cuidado e, portanto, um risco. Nessa perspectiva, entendem que fazer a mamografia se torna uma obrigação. Num estudo qualitativo com 138 participantes, desenvolvido em Chicago/EUA, o cuidado com a mama constituía uma questão de "vida ou morte", portanto, o rastreamento para o câncer de mama era visto como imprescindível. ${ }^{22}$ Fato que corrobora com as participantes do es- tudo iraniano, em que o comportamento de realizar exames preventivos esteve relacionado com a responsabilidade individual da mulher, com o intuito de preservar a vida. ${ }^{11}$

Uma das mulheres do presente estudo referiu o incentivo dos profissionais para a realização da mamografia, mas sem imposição:

Eu sou elogiada, porque aqui [USF] quando eu vou para fazer, [...] a enfermeira diz: "Vou the pedir a sua mamografia, está bem?" Não tem problema não [...], e lá quando eu faço, que bom, elas dizem e são alegres. Aquelas doutoras para atender e conversando com a gente, e ainda elas dizem que bom que a senhora apareceu para fazer, elas dizem assim [...]. Uma coisa, eles não obrigam, tu vais se tu quiseres fazer, mas elas ficam faceiras que a gente faz (Santiaga, 54 anos de idade).

Santiaga afirma que os profissionais da saúde não a obrigam a realizar a mamografia, entretanto, demonstram satisfação e a elogiam por ter esse cuidado com a saúde. A partir desse depoimento, observa-se que os profissionais da saúde, de modo subliminar, podem influenciar pacientes a realizarem os exames preventivos do câncer de mama, por meio de elogios e demonstração de concordância com o comportamento que consideram ser positivo no âmbito da saúde preventiva.

Na literatura, existe a premissa de que é necessária a disseminação de informações sobre a mamografia para a população feminina, de todos os níveis sociais e econômicos. Com vistas à promoção da equidade para os exames preventivos e incentivo a sua adesão, pois, consideram que essa ação influencia na redução da mortalidade pela neoplasia mamária. ${ }^{23}$ 
No que tange à mamografia, a periodicidade e a faixa etária variaram de acordo com o conhecimento e o entendimento das participantes do estudo. Assim, verifica-se que a periodicidade anual e a faixa etária dos 40 anos de idade estão no ideário das mulheres.

É pelo postinho, eu peguei a mamografia mesmo. [...] a partir dos 40. E o bom seria uma vez no ano, fazer todos os anos assim para ir acompanhando (Vanda, 44 anos de idade).

A doutora explicou que não tendo na família a doença [...], de ano em ano que a gente faz [mamografia]. Agora se tiver, ai a gente tem que ter mais cuidado com certa idade. Quanto mais a idade vai avançando, ai se faz com mais frequência, se não é de ano em ano (Mari, 51 anos de idade).

O conhecimento em relação à faixa etária e a periodicidade possivelmente podem estar atrelados ao saber dos profissionais que as atenderam ao longo dos anos e que as recomendavam dessa maneira. Contudo, somente uma participante tem o conhecimento de que o preconizado para a realização da mamografia é a partir dos 40 anos de idade.

Em um estudo sobre mamografia 39 $(46,4 \%)$ relataram que deveria ser feita a partir dos 40 anos de idade, enquanto apenas quatro $(4,8 \%)$ referiram ser a partir dos 50 anos de idade. ${ }^{16}$ Conforme autores de uma pesquisa, existem fatores que estão relacionados à mamografia anual na população feminina dos 40 a 69 anos de idade. Entre as adultas, fazer o exame anualmente tem relação com o plano de saúde privado. Já para as idosas, ter estudado mais de cinco anos, possuir renda familiar mais elevada e ter companheiro, aumentou a possibilidade de realização do exame. ${ }^{23}$
Em uma pesquisa realizada no Canadá, utilizando a técnica de grupo focal, as mulheres que eram adeptas da detecção precoce do câncer de mama e aquelas com 50 anos de idade ou mais também acreditavam que a mamografia deveria ser realizada a partir dos 40 anos de idade, e não aos $50 .{ }^{19}$

Ademais, no presente estudo, uma das participantes referiu a periodicidade de dois em dois anos e destacou que foi após uma lei governamental, estendeu-se o exame para esse intervalo de tempo, embora ela afirme que gostaria de fazer anualmente:

\begin{abstract}
Eu comecei a fazer a partir dos 40 anos, mas agora eu não sei porque mudou algumas coisas, até eu tinha que fazer todos os anos. Agora, quando eu levei para ela, já me disse que tinha aumentado o tempo, quando não tinha nada assim para controle que era de dois em dois anos. Eu acho que deveria ser feito todo ano, eu queria fazer todo ano se eu pudesse. Mas ela disse que para mim só de dois em dois, que tem que ser mais quem tem alguma coisa, que esses sim têm que ter mais controle [...]. Ela me disse que foi uma lei do governo que tinha dito que era de dois em dois anos (Márcia, 48 anos de idade).
\end{abstract}

Verifica-se que pode haver uma nova construção da periodicidade da mamografia por parte da população, sendo estabelecido bienal, o que converge com a recomendação de 2015 do Ministério da Saude. ${ }^{6}$ Mesmo que a participante tenha esse conhecimento, expressa seu desejo do exame ser mantido anualmente. Também fica implícito que a rotina mais frequente deve ser para mulheres sintomáticas.

É nesse contexto que fica evidente a carência de autonomia das pessoas em relação à opção pelas tecnologias de cuidado, já que essas são direcionadas pelos profissionais, pela rede de atenção e pelas determinações 
dos programas governamentais. Assim, a decisão final não é em conformidade com o desejo de quem usa os serviços de saúde. ${ }^{24}$

As divergências relativas ao rastreamento fazem parte da experiência das mulheres que buscam o cuidado das mamas, o que certamente influenciará nas suas decisões. Para a Sociedade Brasileira de Mastologia, as diretrizes propostas pelo Ministério da Saúde, contrárias à mamografia de rastreamento a partir dos 40 anos de idade, podem aumentar a mortalidade pelo câncer de mama, sendo ressaltado que isso não poderia acontecer devido à dimensão da doença no Brasil.

Diante da problemática exposta, verifica-se que foi construída a prática do exame mamográfico a partir dos 40 anos de idade na USF do estudo. E com as novas recomendações em âmbito nacional do Ministério da Saúde, ela vem se modificando, porém, nem todas as participantes possuíam tais conhecimentos.

Nesse sentido, torna-se emergente a construção do saber com as mulheres, em relação às recomendações do Ministério da Saúde, seus direitos, riscos e benefícios da mamografia de rastreamento para que elas tenham possibilidades de decidir o que consideram melhor para a sua saúde. Além disso, entende-se que o profissional que atua na linha de frente do cuidado se configura um elemento "chave" para colaborar nesses processos decisórios e na definição conjunta com o cuidado de qual é o melhor caminho a seguir: rastrear ou esperar os sintomas de uma doença como o câncer de mama surgirem. Contudo, é necessário destacar e entender que esses profissionais não são os responsáveis pelas recomendações e estratégias propostas pelos órgãos governamentais, e que necessitam seguir os protocolos estabelecidos.

Algumas mulheres não têm certeza quanto às recomendações para o rastreamento por mamografia, revelando dúvidas quanto à periodicidade e a faixa etária. As incertezas permeiam a vida das mulheres e podem fazer com que fiquem vulneráveis ao desenvolvimento da doença e sejam influenciadas na decisão e na compreensão quanto às atividades preventivas.

O atraso na realização da mamografia, segundo uma participante deste estudo, tem relação com a priorização de outras atividades, como as laborais:

Deve fazer uns seis anos que eu não faço mamografia. [...] Sou muito relaxada para mim, para os outros eu corro atrás e incentivo [...]. Eu fiz quando estava lá [zona rural], mas depois não fiz mais, depois eu vim para cá. A vida da gente muda e tu acaba relaxando. Dando prioridade a outras coisas, dei muita prioridade ao trabalho, a trabalhar e deixei a minha saúde em $17^{\circ}$ plano. Não corri mais atrás de nada para mim (Celina, 51 anos de idade).

A participante menciona outras prioridades nas atividades da vida diária ao invés de fazer a mamografia, em virtude do trabalho e da sua rotina e, até mesmo, atribui um desleixo com o próprio corpo. Entende-se que socialmente não é aceito faltar ao trabalho para atividades de prevenção a doenças, somente na vigência delas é que a ausência se torna plausível de justificativas. Nesse contexto, muitas vezes o trabalho e o cuidado com outras pessoas vêm em primeiro lugar, para posteriormente a prevenção e os cuidados à sua saúde.

Na concepção de dez mulheres diagnosticadas com câncer de mama em Ara- 
caju/SE, existiam barreiras socioculturais na fase de detecção da doença, tais como carência de informação em relação ao câncer, tabus, crenças, temor do diagnóstico e terapêuticas, angústia e impotência, comorbidades, vergonha do corpo, além do cuidado com familiares e a impossibilidade de faltar às atividades laborais para cuidar da própria saúde. ${ }^{25}$ Embora as experiências sejam em fases distintas da vida das mulheres (sem e com a doença), observa-se certa semelhança com este estudo, uma vez que as barreiras "causa" de dificuldade de realização dos exames preventivos foram semelhantes.

Nessa perspectiva, Celina utiliza exemplos para falar de algumas "condições" que poderiam ser identificadas a partir da realização do exame mamográfico, o que também estabeleceu as condutas posteriores e a periodicidade da mamografia:

Estou esperando para fazer e esperar o resultado para ver o que vão dizer. [...] Conforme o resultado, fazer mais seguido ou deixar quieto também. Em time que está ganhando não se mexe. [...] é igual a mamografia. Dependendo do resultado, eu vou ver o que fazer ou não, que a médica vai me dizer: "Celina, tu estás com problema assim, vamos tratar ou não vamos tratar". Ou se aparecerem os nódulos anteriores, continuando benignos, eu vou ficar na minha (Celina, 51 anos de idade).

A partir das explicações metafóricas da mulher "em time que está ganhando não se mexe" fica evidente o senso comum, de que em muitos casos, os exames preventivos como a mamografia podem suscitar condutas desnecessárias para algo que pode estar alterado no organismo, entretanto, que não traz malefícios.
Conforme um estudo, o rastreamento da população pode constituir riscos ao invés de benefícios em consequência das intervenções necessárias para chegar a um diagnóstico definitivo ou não, constituindo em atitudes iatrogênicas. Ainda, "muito serão chamados, poucos os escolhidos...", "mas muitos serão prejudicados para que pouquíssimos sejam 'curados". ${ }^{26} \mathrm{O}$ que vai ao encontro do pensamento da participante da pesquisa.

Nesse sentido, ao pensar na saúde pública, na ética da justiça distributiva e nos restritos recursos da saúde, os programas de rastreamento minimizam os recursos econômicos que deveriam ser preferencialmente investidos na terapêutica e no cuidado das pessoas que têm alguma doença. Além do mais, acredita-se que para as pessoas saudáveis pode ocasionar uma doença real oriunda do dano da intervenção sobre o corpo saudável, gerando ônus para o sistema de saúde e para a sociedade. ${ }^{26}$

Também, algumas mulheres deste estudo ouviram falar que fazer em demasia a mamografia poderia ser prejudicial à saúde, criando expectativas negativas quanto ao exame:

O que eu vou fazer, vou estar mexendo em um troço que não está incomodando, não está doendo, não está fazendo nada. Então não tem fundamento isso (Celina, 51 anos de idade).

Ouvi assim um comentário, até um médico comentou que quando eu consultei que se fazer demais prejudica, fazer o tempo certo não, foi o que eu entendi. Ele usou a palavra, só que agora não me lembro [...], nem sei dizer também aquela palavra que ele usou [...] para me dizer no que prejudicaria [...]. Acho que o organismo, mesmo assim, prejudicaria os seios mesmo, prejudicaria se fazer demais, pelo menos o que eu entendo (Mari, 51 anos de idade). 
Até falaram que podia fazer mal. Como é que a gente diz, o raio-X, aquilo, mas eu não sei se é verdade ou não. Não lembro quem falou, mas foram pessoas, assim, mulheres que nem eu assim. O profissional nunca ninguém me falou (Marcia, 48 anos de idade).

Observa-se nas declarações a visão de que o aumento na frequência das mamografias pode causar um efeito deletério, portanto, realizar em demasia é um risco. A reprodução desse conhecimento ocorre em diferentes espaços, seja no âmbito da saúde, seja com pessoas conhecidas do meio social. Nesse sentido, nota-se que no senso comum também há menção que o exame mamográfico pode ser danoso.

De 46 participantes de um estudo canadense, oito relataram a opinião sobre a mamografia e a questão do falso positivo. Dessas, seis expressaram que os danos eram maiores do que os benefícios. Em contrapartida, duas acreditavam que a possibilidade de salvar a vida era mais importante. ${ }^{19} \mathrm{Na}$ pesquisa desenvolvida no Reino Unido, muitas mulheres também tinham ciência de que a mamografia poderia ocasionar riscos, como os falsos positivos e a indução de um câncer. ${ }^{20}$

Todavia, em um estudo foi evidenciado que algumas mulheres preferiam ser excessivamente diagnosticadas a ser subdiagnosticadas quando se trata do câncer de mama. Essa concepção fez parte dos depoimentos, principalmente das mulheres que já haviam participado do rastreamento anteriormente. A maioria permaneceu com as ideias iniciais a respeito da participação positiva no rastreamento, pois citavam que poderiam ter garantia de que não tinham câncer, esperavam saber se a doença estava presente e possibilitar o diagnóstico precoce, tendo a expectativa da terapêutica ser mais bem-sucedida. ${ }^{27}$

Já uma participante deste estudo discorre que não queria fazer a mamografia:

Eu tenho a impressão que a mamografia machuca, e aí que dá essas coisas (Graciela, 41 anos de idade).

Nesse depoimento, fica evidente que a participante crê que o exame pode trazer malefícios para o seu corpo. $\mathrm{O}$ que se assemelha à visão de equatorianas, que participaram de um estudo cujos resultados apresentaram que se uma pessoa sã fizer a mamografia pode desenvolver a doença. ${ }^{28}$

Nos diálogos com as mulheres, o ultrassom foi um dos exames mencionado como prática de cuidado e de prevenção ao câncer de mama. Sobretudo, na vigência de suspeitas da doença, como os nódulos e o aspecto de casca de ovo descrito nos exames prévios.

Algumas vezes tem dado como casca de ovo, então eles ficam meio em dúvida, vamos fazer um ultrassom para ver. Eu vou lá e faço o ultrassom, dá tudo bem, não tem nada. Então, é só o medo mesmo que a gente tem (Valéria, 50 anos de idade).

O ultrassom é salientado na conjuntura da suspeita, da dúvida, do controle e do acompanhamento de nódulos mamários a fim de identificar se eles aumentaram ou não. Desse modo, é considerado relevante para as participantes, como um exame complementar.

Em um estudo em Bebedouro/SP, com 30 mulheres, o ultrassom havia sido realizado por $30 \%$ delas ao menos uma vez, sendo que 16,6\% referiram história de nódulo benigno. Concluiu-se pelos autores que as medidas de prevenção realizadas pelas mu- 
lheres oportunizam a detecção precoce do câncer de mama. ${ }^{29}$

Outros cuidados, como não machucar as mamas para evitar o câncer, também foi salientado pelas mulheres deste estudo:

Eu tenho medo de machucar meu seio, eu já recebi vários convites para jogar, que eu adoro jogar futebol, mas eu tenho medo [...]. Morro de medo de estar jogando, dar uma pechada e depois dar problema (Graciela, 41 anos de idade). A gente deve cuidar para não bater com a mama, dizem que é muito perigoso bater, pode até causar algum nódulo, alguma coisa. Então eu procuro sempre me cuidar para não bater, [...] seio é muito delicado (Maria 2, 57 anos de idade).

$\mathrm{Na}$ cultura das participantes do estudo, fica evidente que machucar a mama é um fator de risco para o câncer, desse modo, elas utilizam estratégias em seu cotidiano para minimizar esse risco, como não participar de práticas esportivas, e ter cuidado para não haver contusão. Fato esse também encontrado em uma pesquisa, em que entre outras causas para o câncer de mama, está o trauma físico. ${ }^{14}$

\section{CONSIDERAÇões FINAIS}

Para as participantes do estudo, a prevenção do câncer de mama está atrelada principalmente aos exames de detecção precoce da doença, como o autoexame, a mamografia e o exame clínico das mamas. Contudo, parte das mulheres destacou os cuidados para a prevenção primária da doença.
Evidenciou-se que, para as mulheres do estudo, as atividades curativas e os exames disponibilizados nos serviços de saúde são mais relevantes, e ocorrem com mais frequência nas Unidades Saúde da Família, em comparação com as atividades preventivas e de conscientização. O que dificulta as ações primárias e pessoais para a prevenção do agravo, apesar de todas as formas de cuidado serem preventivas, quanto curativas, e indispensáveis no cenário da saúde.

Ademais, o grupo apresentou semelhanças quanto à busca pelos serviços, modos de evitar e descobrir o câncer de mama precocemente, periodicidades, locais oportunos para as práticas de cuidado, dessa maneira, partilharam saberes para a prevenção da doença. Em contrapartida, existiam saberes únicos, experiências de vida, desejos e temores em relação ao tema, o que demonstra a singularidade de cada mulher.

Diante do contexto exibido, não foi possível apresentar generalizações quanto ao tema. Entretanto, é possível salientar que as mulheres deste estudo conheciam e praticavam estratégias de prevenção do câncer de mama, especialmente as relacionadas à prevenção secundária. Sendo assim, é evidente a necessidade de a prevenção do câncer de mama ser pauta de estudos, de diálogos entre os profissionais, para as mulheres atendidas e para a comunidade em geral, uma vez que há informações, porém, também existem muitas dúvidas que necessitam ser esclarecidas por meio de ações educativas. 


\section{REFERÊNCIAS}

1. Marques CAV, Figueiredo EM, Gutiérrez MGR. Políticas de saúde pública para o controle do câncer de mama no Brasil. Rev Enferm UERJ. 2015; 23 (2): 272-8.

2. Ohl ICB, Ohl RIB, Chavaglia SRB, Goldman RE. Ações públicas para o controle do câncer de mama no Brasil: revisão integrativa. Rev Bras Enferm. 2016; 69 (4): 798-803.

3. Fonseca MRCC, Torres LM, Traldi MC, Morais SS, Paula BJMM. Risco para câncer de mama e medidas preventivas entre mulheres de uma comunidade acadêmica. Perspectivas Médicas. 2017; 28 (2): 41-50.

4. Gonçalves CV, Camargo VP, Cagol JM, Miranda B, Mendoza-Sassi RA. O conhecimento de mulheres sobre os métodos para prevenção secundária do câncer de mama. Cienc Saude Colet. 2017; 22 (12).

5. Braun V., Clarke V. Using thematic analysis in psychology. Qualitative Research in Psychology. 2006; 3 (2): 77-101.

6. Ministério da Saúde. Instituto Nacional de Câncer José Alencar Gomes da Silva. Diretrizes para a detecção precoce do câncer de mama no Brasil. Rio de Janeiro: INCA; 2015.

7. Ministério da Saúde. Instituto Nacional de Câncer José Alencar Gomes da Silva (INCA) [homepage da Internet]. Rio de Janeiro (RJ); 2014 [acesso em: 2017, set. 27]. Câncer de mama: é preciso falar disso. Disponível em: http://bvsms.saude.gov.br/bvs/publicacoes/cancer_mama_preciso_falar_disso.pdf

8. Conway E., Wyke S., Sugden J., Mutrie N., Anderson AS. Can a lifestyle intervention be offered through NHS breast cancer screening? Challenges and opportunities identified in a qualitative study of women attending screening. BMC Public Health. 2016; 16: 1-9.

9. Gonzalez P., Lim JW, Wang-Letzkus M., Flores KF, Allen KM, Castañeda SF, et al. Breast Cancer Cause Beliefs: Chinese, Korean, and Mexican American Breast Cancer Survivors. West J Nurs Res. 2015; 37 (8): 1.081-99.

10. Derenzo N., Costa MAR, Melo WA, Costa CKF, Francisqueti V., Bernuci MP. Conhecimento de mulheres sobre fatores relacionados ao câncer de mama. Rev Enferm UFSM. 2017; 7 (3): 436-47.

11. Khazaee-Pool M., Montazeri A., MajlessiF., Foroushani AR, Nedjat S., Shojaeizadeh D. Breast cancer-preventive behaviors: exploring Iranian women's experiences. BMC Women's Health. 2014; 20 (4): 638-47.

12. Jung W., Kieling EF, Kunzler IM, Lazzari DD, Nascimento ERP, Alves DLF. Fatores de risco para câncer de mama no setor calçadista. Rev Baiana Enferm. 2014; 28 (2): 145-55.

13. Albini A., Cavuto S., Apolone G., Noonan DM. Strategies to prevent "bad luck" in cancer. J Natl Cancer Inst. 2015; 107 (10): 1-7.

14. Ferrat E., Le Breton J., Djassibel M., Veerabudun K., Brixid Z., Attali C., et al. Understanding barriers to organized breast cancer screening in France: women's perceptions, attitudes, and knowledge. Fam Pract. 2013; 30 (4): 445-51.

15. Esmeraldo GROV, Oliveira LC, Esmeraldo Filho CE, Queiroz DM. Tensão entre o modelo biomédico e a Estratégia Saúde da Família: a visão dos trabalhadores de saúde. Revista APS. 2017; 20 (1): 98-106.

16. Bushatsky M., Cabral LRC, Cabral JRC, Barros MBSC, Gomes BMR, Figueira Filho ASS. Educação em saúde: uma estratégia de intervenção frente ao câncer de mama. Cienc Cuid Saude. 2015; 14 (1): 870-8.

17. Rodrigues TCGF, Brum IV, Santos JLCT, Juste AM, Laporte EGJ, Laporte BEP. Conhecimento de 820 mulheres atendidas no Hospital Universitário da Universidade Federal de Juiz de Fora sobre autoexame das mamas. Rev Bras Mastologia. 2016; 26 (2): 56-9. 
18. Tramonte MS, Silva PCS, Chubaci SR, Cordoba CCRC, Zucca-Matthes G, Vieira RAC. Atraso diagnóstico no câncer de mama em hospital público oncológico. Medicina. 2016; 49 (5): 451-62.

19. Driedger SM, Annable G., Brouwers M., Turner D., Maier R. Can you un-ring the bell? A qualitative study of how affect influences cancer screening decisions. BMC Cancer. 2017; 17 (1): 1-14.

20. Whelehan P., Evans A., Ozakinci G. Client and practitioner perspectives on the screening mammography experience. Eur J Cancer Care (Engl). 2017; 26 (3): 1-12.

21. Aghdash SA, Ghojazadeh M., Sheyklo SG, Daemi A., Kolahdouzan K., Mohseni M., Moosavi A. Breast cancer screening barriers from the woman's perspective: a meta-synthesis. Asian Pac J Cancer Prev. 2015; 16 (8): 3.463-71.

22. Ragas DM, Nonzee NJ, Tom LS, Phisuthikul AM, Luu TH, Dong X. What women want: patient recommendations for improving access to breast and cervical cancer screening and follow-up. Women's Health Issues. 2014; 24 (5): 511-8.

23. Schneider IJ, Giehl MWC, Boing AF, D’Orsi E. Rastreamento mamográfico do câncer de mama no Sul do Brasil e fatores associados: estudo de base populacional. Cad Saude Publica. 2014; 30 (9): 1.987-97.

24. Frigo J., Oliveira DLLC, Rodrigues RMR, Zocche DAA. A consulta ginecológica e seu potencial para produzir a integralidade da atenção em saúde. Rev Enferm UFPE Online [periódico na Internet]. 2016 [acesso em: 2017, et. 24]; 10 (4): 1.299-306. Disponível em:

https://periodicos.ufpe.br/revistas/revistaenfermagem/article/view/11117/12595

25. Gonçalves LLC, Travassos GL, Almeida AM, Gois CFL. Barreiras na atenção em saúde ao câncer de mama: percepção de mulheres. Rev Esc Enferm USP. 2014; 48 (3): 394-400.

26. Norman AH. Ética médica e rastreamento: em quais evidências deveríamos nos apoiar? Revista Brasileira de Medicina de Família e Comunidade. 2014; 9 (31).

27. Waller J., Douglas E., Whitaker KL, Wardle J. Women's responses to information about overdiagnosis in the UK breast cancer screening programme: a qualitative study. BMJ. 2013; 3 (4): 1-8.

28. Godoy Y., Godoy C., Reyes J. Representaciones Sociales acerca de los Programas de Tamizaje de Cáncer Ginecológico en mujeres Ecuatorianas. Rev Esc Enferm USP. 2016; 50 (esp.): 68-73.

29. Souza L., Bento DN, Simões JLM, Borges JBC, Faria TCC. Prevenção secundária do câncer de mama em mulheres. Arq Cienc Saude. 2014; 21 (1): 55-9.

\section{DAdos DOS AUTORES}

\section{Aline da Costa Viegas}

Doutora em Ciências pela Universidade Federal de Pelotas. Enfermeira Assistencial do Hospital Escola da Universidade Federal de Pelotas, filial Empresa Brasileira de Serviços Hospitalares. Pelotas/ RS - Brasil. alinecviegas@hotmail.com

\section{Rosani Manfrin Muniz}

Doutora em Enfermagem pela Universidade de São Paulo. Professora Aposentada da Faculdade de Enfermagem da Universidade Federal de Pelotas. Enfermeira. Pelotas/RS - Brasil. romaniz@terra. com.br

\section{Daniela Habekost Cardoso}

Mestre em Ciências, Doutorand em Enfermagem pela Universidade Federal de Pelotas. Enfermeira Assistencial da Prefeitura de Pelotas. Pelotas/RS - Brasil. danielahabekost@yahoo.com.br 


\section{Bianca Pozza dos Santos}

Doutora em Ciências pela Universidade Federal de Pelotas. Enfermeira. Membro do Núcleo de Condições Crônicas e suas Interfaces (NUCCRIN). Pelotas/RS - Brasil. bi.santos@bol.com.br

\section{Janaina Baptista Machado}

Mestranda em Saúde Coletiva pela Universidade Federal do Rio Grande do Sul. Pós Graduanda em MBA em Gestão de Pessoas e Liderança pela Faculdade de Educação São Luís. Enfermeira do Time de Acessos Vasculares e Terapia Infusional do Complexo Hospitalar Santa Casa de Misericórdia de Porto Alegre. Porto Alegre/RS - Brasil. janainabmachado@hotmail.com

\section{LUIZ GUILHERME LINDEMANN}

Mestrando em Enfermagem pela Universidade Federal de Pelotas. Bolsista de mestrado pela Coordenação de Aperfeiçoamento de Pessoal de Nível Superior (CAPES). Enfermeiro. Pelotas/RS - Brasil. luguilindemann@hotmail.com

Submetido em: 16-10-2019

Aceito em: 22-6-2020 